\title{
AVALIAÇÃO DE UMA EXPERIÊNCIA DE APLICAÇÃO DE SIMULAÇÃO EMPRESARIAL EM UMA UNIVERSIDADE DO SUDOESTE EUROPEU
}

\section{EVALUATION OF A BUSINESS GAMES IN A UNIVERSITY OF SOUTHWEST EUROPE}

\section{EVALUACIÓN DE UNA EXPERIENCIA DE APLICACIÓN DE SIMULACIÓN EMPRESARIAL EN UNA UNIVERSIDAD DEL SUROESTE EUROPEO}

\section{Janaina Piana}

Doutoranda em Administração pela FGV/EBAPE

Endereço: FGV/EBAPE - Praia de Botafogo, 190 - 4 e 5o andares, CEP: 22250-900. Rio de Janeiro, RJ, Brasil Telefone: (21) 3799-5579

E-mail: janainapiana@hotmail.com

\section{Rolf Hermann Erdmann}

Professor Associado da UFSC, no Programa de Pós-Graduação em Administração Doutorado em Engenharia de Produção pela Universidade Federal de Santa Catarina Endereço: Campus Universitário - Trindade, CEP 88040-900. Florianópolis, SC, Brasil Telefone: (48) 3721-2323

E-mail: rolf.erdmann@ufsc.br

\section{Mayara Teodoro de Oliveira}

Doutoranda em Administração pelo CPGA/UFSC

Endereço: Campus Universitário - Trindade, CEP 88040-900. Florianópolis, SC, Brasil Telefone: (48) 3721-6457

E-mail: teodoromay@hotmail.com

\section{Beatriz Marcondes de Azevedo}

Professora da Faculdade Capivari - FUCAP

Doutorado em Engenharia de Produção pela Universidade Federal de Santa Catarina Endereço: João Januário da Silva, 6555, Ratones, CEP 88052-200. Florianópolis, SC, Brasil Telefone: (48) 3623-6000

E-mail: biabizzy@gmail.com

Artigo recebido em 12/12/2012. Revisado por pares em 08/06/2013. Reformulado em 24/10/2013. Recomendado para publicação em 03/03/2014 por Ademar Dutra (Editor Científico). Publicado em 29/08/2014. Avaliado pelo Sistema double blind review.
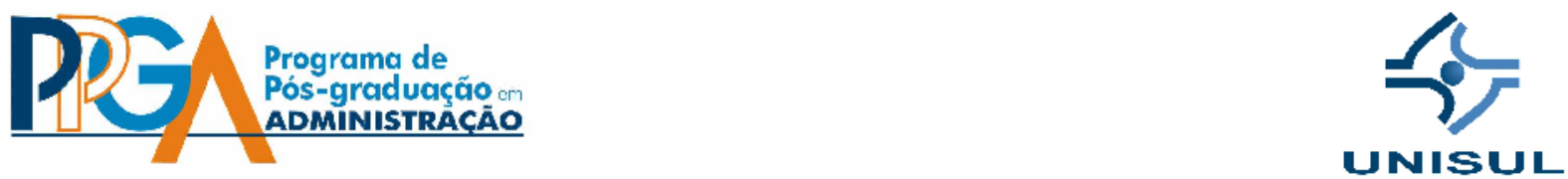

\section{(1) (9)}

(6r no No C Copyright 2008 UNISUL-PPGA/Revista Eletrônica de Estratégia \& Negócios. Todos os direitos reservados. Permitida citação parcial, desde que identificada a fonte. Proibida a reprodução total. 
RESUMO

O presente artigo teve como objetivo avaliar uma experiência de simulação empresarial a partir de três dimensões: funcionamento operacional do Jogo, o método de ensino através da simulação com Jogos de Empresa, e a aprendizagem do aluno. A aplicação da simulação ocorreu em duas turmas de graduação em Administração em uma Universidade Portuguesa. A partir dos resultados, pode-se inferir que a prática da simulação empresarial levou ao incremento da base teórica aos alunos, bem como se concluiu que o ato de jogar é positivo, e pode servir de apoio à aprendizagem. Ao final, sugestões foram apontadas visando ao aperfeiçoamento do novo modelo, a fim de consolidar uma ferramenta que contribua no processo de ensino-aprendizagem em Administração.

Palavras-chave: Simulação Empresarial; Jogos de Empresa; Sistema de Produção; Ensino e Aprendizagem.

\section{ABSTRACT}

This article intends to evaluate an experience of business simulation under three aspects: operational functioning of the Game, the teaching method through Business Games, and student learning. The application of the simulation occurred in two undergraduate business classes at a Portuguese University. From the results, it was possible infer that the game increased the students theoretical basis, as well as playing is positive and can help their learning. Finally, suggestions were pointed aiming to improve the new model in order to build a tool that helps in business teaching and learning.

Keywords: Business Simulation; Business Games; Production Systems; Teaching and Learning.

\section{RESUMEN}

Este artículo tuve por objetivo evaluar una experiencia de simulación empresarial desde tres juegos de empresa, y el aprendizaje de los alumnos. La aplicación de la simulación ocurrió en dos grupos de alumnos del curso de Administración en una universidad de Portugal. Desde los resultados es posible inferir que la práctica de simulación empresarial llevó al incremento de la base teórica a los alumnos, así como se concluyó que jugar es positivo, y puede ayudar el aprendizaje. Al final fueron apuntadas sugerencias para perfeccionamiento del modelo con fines de consolidar una herramienta de contribución en el proceso de enseñanza y aprendizaje en Administración.

Palabras-clave: Simulación Empresarial; Juegos de Empresa; Sistema de Producción; Enseño y Aprendizaje. 


\section{INTRODUÇÃO}

Os profissionais de Administração decidem diante de inúmeras circunstâncias e problemas utilizando suas experiências, conhecimentos, habilidades, valores e intuição. Diante disso, os gestores têm buscado formas mais estruturadas para lidar com a imprevisibilidade e incertezas da tomada de decisão, como forma de assegurar a competitividade organizacional e a sustentabilidade dos negócios.

Neste contexto, os cursos de Administração devem investir na formação de gestores qualificados e, principalmente, no desenvolvimento do aprendizado sistêmico das diversas áreas da ciência administrativa para auxiliar no desempenho profissional, requerendo, portanto, repensar sobre os métodos de ensino-aprendizagem utilizados.

No VI Encontro de Coordenadores de Cursos de Administração (CRA, 2011) debateu-se sobre o ensino e o mercado da Administração e a conclusão de especialistas de diferentes partes do Brasil foi de que a maioria das IES (Instituições de Nível Superior) possui dificuldades para atender a necessidade de oferecer uma formação mais robusta aos estudantes.

Segundo Andrade et al (2004) e Sauaia et al (2010), existe um gap entre a formação dada por tais cursos e as expectativas do mercado de trabalho. Por receberem inúmeras críticas nesse sentido, os coordenadores passaram a perceber a urgência de se adotar metodologias ativas, que estimulem a autonomia e propiciem o protagonismo dos alunos através do debate, da interação, do pensamento coletivo, despertando a inteligência e desenvolvendo um repertório de competências profissionais e sociais.

Consoante com a realidade apresentada, os jogos de empresas surgem como método de ensino que integra a teoria à prática, podendo promover a preparação de profissionais mais competentes para enfrentar o mercado de trabalho. Logo, o uso de simuladores organizacionais concomitante ao ensino tradicional vem potencializando a melhoria da qualidade da formação (CARNIEL, 2002; GERBER, 2000; BERENDS; ROMME, 1999; SILVA, 1998; FARIA, 1997).

Revista Eletrônica de Estratégia \& Negócios, Florianópolis, v.7, n.2, mai./ago. 2014. 
Ao buscar potencializar o ensino de Administração, foi desenvolvido um simulador organizacional pelos integrantes do Núcleo Interdisciplinar de Estudos em Gestão da Produção e Custos (NIEPC/UFSC). O simulador é aqui entendido, com base nos pressupostos de Sauaia (2008), como um artefato educacional, e o jogo como a dinamização do simulador. Assim, o presente artigo tem como objetivo avaliar os resultados da aplicação desse artefato no comportamento e aprendizagem dos alunos do curso de Administração de uma Universidade de Portugal.

\section{JOGOS EMPRESARIAIS}

Simulação de Gestão Empresarial, também chamada de Simulador Organizacional, Jogo de Gestão, Jogo de Empresas, Jogo Empresarial, Jogo de Negócios ou Business Games, são termos que se apresentam como instrumento didático, cujo objetivo é levar o aprendiz a vivenciar situações semelhantes à realidade, permitindo avaliá-la por meio da análise das possíveis consequências decorrentes do processo decisório subjacente. Desenvolvido através de um modelo matemático que determina as características técnicas, organizacionais e administrativas das empresas e as relações destas com o meio, o jogo favorece o desbloqueio psicológico que possa existir no aprendiz, além de desenvolver habilidades, como abstrair, organizar e usar informações, prever e planejar, combinar papéis de generalista e especialista, auxiliar no trabalho em grupo, processar informações importantes e experimentar novas ideias (TANABE, 1977; MARTINELLI, 1987, SAUAIA, 1995; LÈGER, 2006).

Ben-Zvi (2010) e Rafalski e Carneiro (2013) complementam afirmando que os jogos de empresas apresentam uma alternativa eficaz para o ensino tradicional, pois são vistos como método de ensino que integra a teoria à prática. Através deles, os alunos são levados a vivenciar conceitos aprendidos em sala de aula.

Na simulação, os problemas são interligados e a execução da tomada de decisão passa a ser global. Portanto, o simulador pode ser considerado um método pedagógico completo para o crescimento e integração dos conhecimentos. Do ponto de vista da aprendizagem, a simulação introduz a vocação indutiva, onde as conclusões são tiradas a partir de casos particulares, como a experiência singular do aluno participante, onde ele 
tende a chegar a conclusões mais gerais a respeito do assunto que está sendo simulado (ARBEX et al, 2006; MAHBOUBIAN, 2010).

Em relação às vantagens à adesão aos jogos empresariais, mencionam-se: maior compreensão dos conceitos; conscientização da necessidade de um realinhamento atitudinal e comportamental no atual momento de mudanças; maior possibilidade de comprometimento grupal com resultados; reconhecimento do próprio potencial e das dificuldades individuais; resgate do lúdico, do potencial criativo e descoberta de possibilidades não consideradas anteriormente; possibilidade de mensuração de resultados durante os jogos simulados, permitindo avaliações comparativas com a realidade empresarial; maiores chances de desenvolvimento de habilidades técnicas, conceituais e interpessoais, tais como habilidade de negociação, trabalho em equipe e desenvolvimento de estratégias (GRAMIGNA, 1995; MARQUES FILHO, 2001; GROFF, et al, 2010).

Pressupõe-se que, com os jogos empresariais, os estudantes têm a possibilidade de praticar os conceitos teóricos e ainda refletir sobre o processo decisório nas organizações; ou seja, torna-se possível melhorar a interação entre prática e resultado por decidirem em condições próximas às reais, contribuindo para uma formação mais robusta (BERNARD, 2006). Sendo assim, a integração da prática com a teoria é a principal vantagem da simulação gerencial (SAUAIA, 1995; PROTIL; FISCHER, 2005; BERNARD, 2006). Ruas (2003) acrescenta que, no ato de jogar, amplia-se a capacidade do participante relacionar cenários, perspectivas, situações e variáveis de diferentes origens e naturezas.

Cabe ressaltar que os jogos de empresa permitem a integração de conhecimentos adquiridos, de forma isolada, nas diversas disciplinas, proporcionando uma visão holística do funcionamento integrado de uma empresa (BERNARD, 2006; PROTIL; FISCHER, 2005; LACRUZ; VILLELA, 2005), bem como o desenvolvimento de aspectos comportamentais, tais como estilos de liderança e trabalho em equipe (BERNARD, 2006; LACRUZ; VILLELA, 2005).

Segundo Bernard (2006) e Sá Silva et al (2011), a simulação, como metodologia de ensino, centraliza a aprendizagem nos problemas apresentados ao estudante, que analisa as possibilidades a serem adotadas e decide qual delas utilizar para resolução do problema 
em foco, responsabilizando-se em grande parte pelo seu próprio ensino. Portanto, a utilização desse artefato no ensino-aprendizagem traz a vantagem do envolvimento das pessoas em uma atividade na qual, além de vivenciá-la, têm a oportunidade de analisar o processo de forma crítica, extrair insights úteis desta análise e aplicar o aprendizado em seu cotidiano (GRAMIGNA, 1995).

Nestes termos, os jogos empresariais surgem como alternativa para o desenvolvimento de melhorias no ensino-aprendizagem, constituindo-se em esforço considerável para compreender melhor a integração entre a teoria e a prática, podendo, assim, serem utilizados como uma ferramenta educacional (SAUAIA, 1995; 2008).

Considerado como ferramenta educacional, os jogos empresariais vão permitir um preparo mais adequado de gestores e alunos através da simulação de processos, que serão encontrados na realidade empresarial. Sendo assim, os jogos são caracterizados por dois pontos de vista; um didático, por apresentar-se como um novo formato de aula; e outro que envolve o fator empresarial, possibilitando a adaptação dos estudantes no seu futuro campo de trabalho (BERRETINI e CAMPOS, 2010).

Desta forma, os jogos empresariais caracterizam-se como ferramenta de simulação da realidade, e têm como principal objetivo apresentar, aos participantes, os modelos de gestão em um ambiente seguro e sem risco, proporcionando, aos jogadores, atuar em uma simulação do seu futuro campo de trabalho, sem colocar em risco a sobrevivência de nenhuma empresa do mundo real (PRETTO et al, 2010).

\subsection{AVALIAÇÃO EM JOGOS EMPRESARIAIS}

Nos cursos de graduação em Administração, o uso dos jogos de empresa tem se intensificado com a utilização do computador como ferramenta de apoio pedagógico. A utilização das novas tecnologias tem provocado diferentes impactos na educação. As descobertas digitais introduzem novo comportamento na forma como as informações são absorvidas, tornando o indivíduo mais ativo no processo de aprendizagem. O uso da $\mathrm{TI}$ subsidia o desenvolvimento do protagonismo dos alunos, tornando-os autodidatas e 
dificultando a aceitação dos métodos tradicionais de ensino, de onde decorre o grande incremento ao uso de jogos empresariais (TAPSCOTT, 1997; ARBEX et al, 2006).

No que se refere à aprendizagem por meio da vivência, como o caso dos jogos empresariais, ela ocorre através de um processo quadrifásico, iniciando com uma experiência concreta, seguida da observação e reflexão sobre aquela experiência. Posteriormente, formam-se conceitos abstratos e generalizações sobre o fenômeno vivenciado, cujas implicações serão testadas em novas experiências. Nos jogos, a cada rodada de tomada de decisões e análise dos resultados, as quatro fases da aprendizagem vivencial estão presentes (KOLB et al, 1978).

Quanto às avaliações de aprendizagem, as concepções mais recentes baseiam-se nos princípios de que "educar é formar e aprender é construir o próprio saber" (HAIDT, 1995, p. 286), o que torna importante avaliar todo o processo de ensino-aprendizagem. Com isso, o autor afirma que o processo de avaliação está ligado ao de aprendizagem, sendo este planejado, pensado e realizado de forma coerente.

Tradicionalmente, o método de avaliação mais utilizado nas disciplinas de jogos de empresas, na graduação, é aquele baseado no desempenho das companhias fictícias. Partindo do pressuposto de que as melhores empresas são aquelas onde se obteve maior rendimento, o que, automaticamente, teria resultado em maior aprendizado por parte dos alunos. Essa característica pode ser verdadeira em alguns casos, mas deve ser analisada a fim de compreender a dinâmica do processo de ensino-aprendizagem (STAHL e LOPES, 2004).

Na pedagogia atual é discutida a importância do erro no processo de aprendizagem (HOFFMAN, 1997 apud STAHL; LOPES, 2004), pois, quando ele é percebido, tende a desencadear um processo de reflexão, levando o aprendiz a verificar porque errou e o que deveria ter feito. Com essa reflexão é possível identificar novas situações e possibilidades. $\mathrm{O}$ acerto não possibilita a reflexão e, deste modo, não se pode considerar que o aluno que errou não aprendeu aquilo que se buscava com a atividade. 
Logo, um dos principais objetivos dos jogos de empresa é o processo de integração e de visão sistêmica. A vantagem se deve justamente à flexibilidade, uma vez que o feedback de informações é aleatório e imprevisível para os participantes, exigindo uma constante reavaliação das decisões, o que proporciona um grau ainda maior de motivação e aprendizado, principalmente porque esta atividade proporciona o processo contínuo de administração (planejamento, avaliação e controle) (STAHL e LOPES, 2004).

Para este estudo, optou-se por avaliar a aprendizagem quanto aos conhecimentos teóricos adquiridos pelos alunos por testes de caráter objetivo, do tipo verdadeiro/falso. As habilidades gerenciais foram associadas ao desempenho da equipe e, para comportamentos e atitudes, usou-se a autoavaliação. As mesmas ferramentas de avaliação foram utilizadas para verificação da adequação da técnica de ensino e do funcionamento do Jogo como um todo.

\section{METODOLOGIA}

Em termos metodológicos, trata-se de uma pesquisa exploratório-descritiva em forma de estudo de caso.

A pesquisa foi realizada por meio da aplicação de um Jogo Empresarial criado pelos integrantes do NIEPC, intitulado RCAP (Relações Complexas na Administração da Produção). O jogo foi desenvolvido com o objetivo de auxiliar e motivar os alunos a adquirir, esclarecer e aperfeiçoar seus conhecimentos, além de desenvolver habilidades de gestão. $\mathrm{O}$ mesmo foi aplicado, em rodada única com duas turmas (diurno e noturno) de formandos do curso de Administração em uma Universidade de Portugal. É importante assinalar que a opção pela única rodada ocorreu em função de limitação temporal por parte da instituição, uma vez foi preciso haver uma etapa pré e pós-simulação, conforme se visualiza no quadro 1.

O Jogo RCAP simula um sistema de produção com subsistemas, entendidos como áreas do sistema produtivo, que interagem com fatores de competitividade. Para construção do artefato, mapearam-se as relações existentes, criando uma modelagem matemática para cada relação, de acordo com a situação da empresa em um dado momento. O participante 
deveria fazer investimentos com uma limitação de $€ 100.000,00$, nas relações que considerasse mais relevantes dentro da situação apresentada. O resultado da performance organizacional deu-se em valores por desempenho em custo, qualidade, confiabilidade, flexibilidade e rapidez.

As etapas de aplicação e avaliação do jogo estão resumidas no Quadro 01:

Quadro 01 - Etapas de aplicação e avaliação do jogo

\begin{tabular}{|c|c|}
\hline Aula & Etapa 1 - Fase de Preparação \\
\hline \multirow{3}{*}{$\begin{array}{l}\text { Primeira (de } \\
50 \text { minutos) }\end{array}$} & Apresentação e exposição a respeito do Jogo empresarial a ser trabalhado. \\
\hline & Disponibilização do Manual do Jogo de Empresarial. \\
\hline & Formação das equipes e aplicação do pré-teste. \\
\hline Aula & Etapa 2 - Aplicação \\
\hline Extraclasse & Primeira rodada do jogo. \\
\hline Aula & Etapa 3 - Finalização \\
\hline \multirow{3}{*}{$\begin{array}{c}\text { Segunda aula } \\
\text { (de } 50 \\
\text { minutos) }\end{array}$} & Apresentação do desempenho final no Jogo Empresarial. \\
\hline & $\begin{array}{l}\text { Aplicação de questionário aos participantes, buscando a avaliação do jogo e a própria } \\
\text { avaliação do aluno quanto ao seu desempenho. }\end{array}$ \\
\hline & Aplicação do pós-teste. \\
\hline
\end{tabular}

Fonte: Elaborado pelos autores.

Para a coleta de dados foram aplicados um pré-teste e um pós-teste (prova individual de 20 questões versando sobre o conteúdo de Administração da Produção). Vale ressaltar que, por serem alunos formandos, todos já haviam concluído a disciplina de Gestão de Operações, também conhecida Administração da Produção. Além disso, o pré-teste foi aplicado após aula expositiva sobre o conteúdo do pré-teste, com objetivo de avaliar o conhecimento do aluno na área antes de sua participação. O pós-teste procurou identificar se houve evolução do conhecimento após a experiência.

Para a avaliação dos resultados nos testes foram comparadas as notas de pré e pós testes das turmas, com o uso do teste estatístico " $\mathrm{t}$ " de student, apropriado para 
comparar dois conjuntos de dados quantitativos em termos de seus valores médios (BARBETTA, 2007). As hipóteses formuladas foram:

$\mathrm{H}_{0}$ : a nota média dos alunos no teste não se altera com o uso do Jogo Empresarial.

$\mathrm{H}_{1}$ a nota média dos alunos no teste aumenta com o uso do Jogo Empresarial.

Ao analisar os resultados, utilizou-se a média da variação da nota nos testes das equipes $(\mathrm{x}$ ) e o desempenho das mesmas no Jogo (y), avaliando a existência de correlação entre as duas variáveis através do coeficiente $r_{s}$ de Spearman. O uso do referido coeficiente ocorreu pelo fato das variáveis de desempenho assumirem valores muito discrepantes. Este coeficiente apresentou-se mais apropriado, pois se utiliza da ordenação resultante da classificação obtida pelos jogadores, e não de seus valores absolutos ou magnitudes (BARBETTA, 2007). As hipóteses estabelecidas foram:

$\mathrm{H}_{0}$ : as variáveis x e y são não correlacionadas;

$H_{1:}$ as variáveis $x$ e y são correlacionadas;

Quanto ao questionário de avaliação do Jogo e da própria participação do aluno como jogador, este foi desenvolvido recorrendo-se a diversos trabalhos anteriores (MILES, BIGGS, SCHUBERT, 1986; SAUAIA, 1997; ARCHER, 1990; JACKSON, 1995; FERRÁNDEZ, SARRAMNA, TARIN, 1977). Desta forma, o questionário continha as seguintes dimensões: Autoavaliação da experiência dos participantes; Participação anterior do estudante em Jogos de Empresas; Estímulos e motivos que contribuíram para o aproveitamento; Benefícios educacionais resultantes, como conhecimentos, habilidades e atitudes; e Compreensão das regras operacionais do Jogo. Os dados extraídos dos questionários respondidos pelos alunos foram analisados a partir da estatística descritiva, focando a exposição das opiniões dos participantes das simulações realizadas.

\section{APRESENTAÇÃO DOS RESULTADOS}

Revista Eletrônica de Estratégia \& Negócios, Florianópolis, v.7, n.2, mai./ago. 2014. 
A partir das informações e da situação operacional da empresa apresentada, as equipes precisaram analisá-las para, então, tomar as decisões. Também cabe lembrar que os testes, questionários e o professor que ministrou a disciplina foram iguais para as duas turmas.

\subsection{NOTAS DOS TESTES}

Ao tomar como base as notas dos alunos nos pré e pós-teste respondidos pelas duas turmas, pode-se afirmar, no teste " $\mathrm{t}$ " para dados pareados, considerando o nível de confiança de $99 \%$, ou uma chance de erro de $1 \%$, e um " $t$ " de 3,89 (Tabela 1) que: - $\mathrm{H}_{0}$ é falsa, detectando, que houve um aumento real do desempenho no teste de conhecimentos teóricos após a aplicação do Jogo.

Ao admitir que não houve qualquer outro fator além da vivência no Jogo, atuando de forma sistemática entre as duas mensurações, pode-se concluir que a participação pode influenciar, de forma contributiva/aditiva, no conhecimento teórico em Administração da Produção.

\subsection{DESEMPENHO DAS EQUIPES NO JOGO}

O desempenho das equipes no Jogo foi analisado para verificar a existência da relação entre o desempenho das equipes no Jogo $(x)$ com o aumento ou redução da nota no pós-teste, quando comparada com o pré-teste (y). Para mensurar a existência de correlação entre estas duas variáveis $(x, y)$ da população, utilizou-se o teste de significância $r_{s}$ de Spearman. O coeficiente de correlação de Spearman é definido por:

$$
\mathbf{r}_{3}=1-\frac{6 \cdot \Sigma^{D^{2}}}{\mathbf{n} \cdot\left(\mathbf{n}^{2}-1\right)}
$$

onde $\Sigma \mathrm{D}^{2}$ é a diferença quadrática entre os postos.

Segundo Barbetta (2007), o valor do coeficiente estará no intervalo entre -1 e 1. Será tão mais próximo de 1 (ou -1) quanto mais forte for a correlação entre os dados observados. Ter-se-á $r_{s}=+1$ se houver uma correlação positiva perfeita. Por outro lado, ter-se-á $r_{s}$ $=-1$ se houver uma correlação negativa perfeita.

Revista Eletrônica de Estratégia \& Negócios, Florianópolis, v.7, n.2, mai./ago. 2014. 
Desta forma, no caso da turma do período diurno, com $n=12$, valor $r_{\text {s diurno }}=0,19$ e nível de significância de 5\%, é possível afirmar que o teste não acusa significância. Não é possível afirmar que existe correlação entre desempenho no Jogo e a média da variação da nota nos testes das equipes.

Também o teste com a turma do período noturno apontou, com $\mathrm{n}=9$, valor $r_{\text {s no- }}$ turno $=0,06$ (Tabela 2), para a rejeição da $\mathrm{H}_{1}$ e aceitação da $\mathrm{H}_{0}$; ou seja, as variáveis x e y são não correlacionadas. Portanto, a correlação positiva fraca $\left(r_{s}\right.$ diurno $=0,19$ e $r_{s}$ noturno $\left.=0,06\right)$, descrita pelos dados, não é suficiente para afirmar a existência de correlação entre as duas variáveis.

Com estes dados pode-se inferir que o bom desempenho alcançado no Jogo não tem relação com o aprendizado relacionado ao conteúdo; em outras palavras, o aluno que errou durante a execução do Jogo pode ter tido melhor aprendizado do que aquele que teve mais acertos nas decisões relacionadas ao Jogo. Na própria pedagogia atual é discutida a importância do erro no processo de aprendizagem (HOFFMAN, 1997 apud STAHL; LOPES, 2004), pois, muitas vezes, o aluno aprende mais nele do que nos momentos em que está acertando. O erro, quando percebido pelo aluno ou apontado pelo professor, tende a desencadear um processo de reflexão, levando o aluno a verificar porque errou e o que deveria ter feito. Refletindo sobre suas atividades e atitudes, aquele que errou consegue identificar novas situações e possibilidades que o aluno que acertou não irá descobrir ou aprender. 0 acerto não gera tal processo de reflexão e, deste modo, não pode ser considerado que quem errou não aprendeu o que o professor almejava com a atividade.

Além disso, de acordo com Stahl e Lopes (2004), os modelos dos jogos de empresas, tradicionalmente, apoiam-se no desempenho da companhia fictícia na simulação para avaliar o nível de aprendizagem obtido pelos participantes. Ao observar os resultados obtidos, portanto, pode-se considerar que o uso exclusivo do desempenho no Jogo não é suficiente para verificar o aprendizado aluno. Corroborando com os autores (STAHL; LOPES, 2004), sugerem-se alternativas para uma avaliação qualitativa que possibilite verificar o aprendizado no que diz respeito aos conhecimentos teóricos, habilidades e atitudes, valorizando ainda mais o uso de simuladores na formação profissional. Snow et al (2002) ressal- 
tam que é também importante que se avalie a influência da participação nos jogos no aumento da confiança e de atitude positiva ; portanto, para a maximização do potencial como uma experiência educacional.

\subsection{QUESTIONÁRIO DE AVALIAÇÃO}

Após a aplicação do Jogo e dos testes, pediu-se aos alunos para que respondessem um questionário estruturado com três perguntas fechadas e uma pergunta aberta. A primeira inquiriu a experiência dos estudantes em participar de outros Jogos Empresariais. Obteve-se, assim, como resposta, que 68\% deles já tiveram vivência com outros Jogos e $33 \%$ nunca haviam participado.

Tal resultado demonstra a oportunidade que se tem para trabalhar e pesquisar novas estratégias de aprendizado no âmbito geral do curso de Administração da Universidade Portuguesa, visto que os participantes são alunos formandos no curso e, portanto, não terão oportunidade de vivenciar o uso de Jogos Empresariais novamente durante o curso em questão.

Com relação à intensidade percebida quanto aos benefícios educacionais alcançados na vivência, como conhecimentos, habilidades e atitudes (FERRÁNDEZ, SARRAMNA, TARIN, 1977), 3\% disseram ser muito alta, 33\% alta, 58\% razoável, e $5 \%$ baixa. Observou-se que o Jogo foi percebido por grande parte dos participantes como um meio para acessar conhecimentos, habilidades e atitudes; portanto, mais do que simplesmente um método lúdico, ele foi capaz de proporcionar aprendizagem. Entretanto, o elevado número da opção razoável (58\%) aponta para inconsistências no Jogo quanto aos benefícios educacionais. Ao analisar os pontos fracos da vivência no Jogo, vários alunos citaram a curta duração e a falta de outras rodadas de aplicação. Estas informações podem levar ao entendimento de que, se houvesse mais rodadas, os benefícios educacionais seriam mais evidentes.

Quanto à dimensão da compreensão das regras operacionais do Jogo (JACKSON, 1995), 63\% declararam haver compreendido as regras pelo menos razoavelmente, enquanto $38 \%$ afirmaram não haver compreendido suas regras. O alto número de alunos (63\%) ter 
compreendido as regras razoavelmente aponta para inconsistências na explanação das mesmas, no Manual do Jogador ou na própria construção do Jogo. Este é um ponto de destaque para reconsiderações a fazer no modelo de Jogo proposto.

Por fim, na quarta pergunta, que estava relacionada aos pontos fracos e fortes da experiência dos participantes no jogo (MILES, BIGGS, SCHUMBERT, 1986), e da operacionalização do regerido jogo, obteve-se, principalmente, as seguintes respostas, como segue no Quadro 02:

Quadro 02: Pontos fortes e fracos de vivência

\begin{tabular}{|c|c|}
\hline Pontos Fortes & Pontos Fracos \\
\hline “Aprendizagem e trabalho em equipe”. & "Não fazer a segunda jogada". \\
\hline $\begin{array}{l}\text { “Como era a primeira vez que, jogava foi positivo } \\
\text { para a minha experiência”. }\end{array}$ & $\begin{array}{l}\text { "Distribuição do capital não ter sido fácil pelos vários } \\
\text { fatores da empresa". }\end{array}$ \\
\hline $\begin{array}{l}\text { "Este jogo demonstra as dificuldades que podemos } \\
\text { encontrar". }\end{array}$ & $\begin{array}{l}\text { "Muitas opções similares, torna-se cansativo para a } \\
\text { leitura e análise". }\end{array}$ \\
\hline “Fácil compreensão". & “Demasiado texto". \\
\hline $\begin{array}{l}\text { "Ser uma ideia inovadora, que deu uma ideia de } \\
\text { como funcionava na prática, ter uma ideia da reali- } \\
\text { dade, e como se combinam as assertivas". }\end{array}$ & "Falta de experiência neste tipo de jogo". \\
\hline "Conhecimento que se adquiriu" & “Discordância no grupo". \\
\hline $\begin{array}{l}\text { "Tentar perceber a dinâmica do jogo, leitura do } \\
\text { manual RCAP para melhor entender os fatores de } \\
\text { prática e resultados". }\end{array}$ & $\begin{array}{l}\text { "Muito tempo despendido em um final de curso, o } \\
\text { que se torna um problema sério, visto que pode } \\
\text { gerar ineficácia". }\end{array}$ \\
\hline $\begin{array}{l}\text { "Conseguimos perceber os vários drivers fundamen- } \\
\text { tais em um processo de produção" }\end{array}$ & $\begin{array}{l}\text { "Não colocar mais aprofundamento do funciona- } \\
\text { mento e do problema de pesquisa". }\end{array}$ \\
\hline $\begin{array}{l}\text { "Realça a intuição de que estamos verdadeiramente } \\
\text { em uma empresa e aumenta as nossas capacidades". }\end{array}$ & $\begin{array}{l}\text { "Informação reduzida apesar de ser um jogo onde } \\
\text { conta o conhecimento e a capacidade de interpre- } \\
\text { tar". }\end{array}$ \\
\hline $\begin{array}{l}\text { "Deu-me uma noção das muitas perspectivas que } \\
\text { são necessárias observar na empresa, como elas } \\
\text { interagem e quais suas relevâncias na empresa". }\end{array}$ & $\begin{array}{l}\text { "O jogo devia ser em formato informático e devia ter } \\
\text { mais do que uma jogada, de modo a poder corrigir } \\
\text { alguns pontos". }\end{array}$ \\
\hline $\begin{array}{l}\text { "Melhorar o nosso conhecimento, pôr em prática os } \\
\text { conhecimentos adquiridos e melhorar a nossa } \\
\text { aprendizagem em relacionamento de grupo". }\end{array}$ & "Falta de experiência em relação a investimentos". \\
\hline “A interação entre os elementos do grupo e a noção & "Verdadeiro conhecimento do funcionamento da \\
\hline
\end{tabular}

Revista Eletrônica de Estratégia \& Negócios, Florianópolis, v.7, n.2, mai./ago. 2014. 


\begin{tabular}{|l|l|}
\hline $\begin{array}{l}\text { de que existem algumas diferenças de opinião que } \\
\text { contribuem favoravelmente para melhores resulta- } \\
\text { dos". }\end{array}$ & empresa". \\
\hline "Alta aplicabilidade no mundo empresarial". & "Não dar grande importância às análises". \\
\hline "Novo modo de aprendizagem". & "Curta duração". \\
\hline
\end{tabular}

Fonte: Elaborado pelos autores.

Além dos pontos fortes e fracos destacados no quadro 2, é importante assinalar que, durante a observação da etapa da aplicação do Jogo, os alunos mostraram-se animados, motivados e comprometidos com o processo de tomada de decisão ao qual eram submetidos. Essa percepção é consoante com os achados do estudo de Ben-Zvi (2010), que concluíram que, pelo fato da vivência despertar tais sensações, os Jogos apresentam-se como alternativa eficaz aos métodos tradicionais de ensino.

Sauaia (2006) já mencionava a importância do aluno aprender fazendo, uma vez que o uso deste recurso possibilita importante interação com seu objeto de estudo, estimulando o autoconhecimento, o exercício da tomada de decisão com responsabilidade e a integração de um trabalho combinado de dimensões diferentes e complementares (razão e emoção), explicitando uma conexão-chave nas organizações, inexplorada no ensino expositivo.

\section{CONCLUSÃO}

O jogo permite que o aluno se insira no mundo real, permitindo experienciar situações que antecipam sua vida profissional. Isto é frequentemente ansiado pelo estudante universitário, na medida em que seu curso avança e ele não vê associação com o que imagina encontrar depois de graduado. Em tempos de grande evasão, mesmo na universidade pública, iniciativas deste tipo são muito bem-vindas.

Dos resultados apresentados pode-se concluir, quanto à avaliação do comportamento e aprendizagem dos participantes e da técnica de ensino, que o Jogo se demonstrou positivo. Através do teste " $\mathrm{t}$ " de student aplicado às notas do pré e pós-teste, pode-se inferir que há uma relação entre o aumento do conhecimento dos alunos e a aplicação do jogo. Em outras palavras, a prática do jogo levou ao incremento da base teórica dos alunos. 
Já quando a média das variações das notas das equipes foi comparada ao desempenho no Jogo, observou-se que este aumento da nota do pré para o pós-teste não estava relacionada com o desempenho obtido no jogo. Isto quer dizer que jogar é positivo e apoia a aprendizagem; porém, vencer não é fator relevante, se correlacionado à aprendizagem.

Ainda, através do questionário de autoavaliação foi possível concluir, por meio da explanação dos alunos, que o jogo demonstrou-se motivador e estimulante pela aproximação com os desafios da realidade de um administrador e pela inovação no processo de aprendizagem. Além disso, os alunos apontaram para benefícios do trabalho em equipe e da aprendizagem de conhecimentos teóricos a partir de uma perspectiva diferenciada.

Ressalta-se, então que, com o Jogo é possível alcançar um conjunto de objetivos em um processo de aprendizagem, onde se consegue aplicar conceitos adquiridos separadamente em diversas disciplinas, pensando como gestor de uma empresa e nos benefícios que pode proporcionar a esta.

Quanto ao funcionamento do Jogo, devem-se levar em consideração alguns aspectos citados como pontos fracos no questionário de autoavaliação. Incluem-se aplicação de curta duração; demasiado texto, que tornou cansativa a análise e leitura do Jogo; bem como a interface do modelo.

Estes resultados, positivos quanto à avaliação do comportamento e aprendizagem dos participantes e da técnica de ensino, e com algumas ressalvas quanto ao funcionamento do Jogo, indicam a necessidade de continuar a busca do desenvolvimento e aperfeiçoamento deste novo modelo de Jogo Empresarial a fim de desenvolver uma ferramenta que contribua no processo de ensino-aprendizagem em Administração.

Destaca-se, finalmente, que o Jogo como ferramenta educacional proporcionará aprendizado desde a primeira fase de sua aplicação, onde acontece a apresentação e exposição a respeito do Jogo empresarial a ser trabalhado; ou seja, a partir da explanação oral do monitor sobre o Jogo, os benefícios educacionais iniciam e vão se tornando mais abrangentes quando acontecem as discussões para solucionar os problemas de gestão e, posteriormente, quando todos compartilham dados e informações sobre sua estratégia para a toma- 
da de decisão dos investimentos no Jogo. Neste momento, há revelações sobre os problemas de gestão apontados nos cenários do Jogo, e também são reveladas as diferentes ações de cada equipe, adotadas para buscar melhor desempenho que os outros jogadores. A aprendizagem individual favorecida pela competição e desenvolvida isoladamente dentro de cada equipe de trabalho, socializa-se no momento do compartilhamento.

Portanto, a relevância deste estudo está em apresentar os Jogos de empresas como ferramenta diferenciada para o aprendizado, que proporcionará não apenas uma forma diferente de ensino, mas também uma maneira diferente de aprendizado, onde a interação entre professor e alunos e entre alunos é o ponto alto. Neste sentido, o estudo fornece contribuições aos interessados em um processo educacional em Administração, capaz de aproximar a teoria da prática organizacional, valorizando ações pedagógicas focalizadas mais na aprendizagem que em ensino doutrinário e pouco atraente.

Quanto às limitações do estudo, destaca-se o número de aplicações do simulador em aula. Por isso sugere-se, como estudos futuros, a utilização do modelo em ambiente de laboratório de pesquisa com aplicações de várias rodadas do Jogo Empresarial.

Além disso, para possibilitar a generalização das conclusões apresentadas neste estudo, entende-se a necessidade de se replicar esta experiência com diferentes populações e com a adoção de outras modalidades de Jogos de Empresas.

\section{REFERÊNCIAS}

ANDRADE, R. O. B. et al. Pesquisa nacional sobre o perfil, formação, atuação e oportunidades de trabalho do administrador. Brasília: CFA, 2004.

ARBEX, M. A. et al. O uso de jogos de empresa em cursos de graduação em administração e seu valor pedagógico: um levantamento no estado do Paraná. In: Anais do XXX ENANPAD, 2006.

ARCHER, E. R. O mito da motivação. In: BERGAMINI, C. W.; CODA, R. Psicodinâmica da vida organizacional, p.3-24. São Paulo: Pioneira, 1990.

BARBETTA, P. B. Estatística aplicada às ciências sociais. Florianópolis: Ed da UFSC, 2007.

BEN-ZVI, T. The efficacy of business simulation games in creating Decision Support Systems: an experimental investigation. Decision Support Systems, vol. 49, p. 61-69. 2010. 
BERENDS, P.; ROMME, G. Simulation as a research tool in management studies. European Management Journal, vol. 17, no. 6, p. 576-583, 1999.

BERNARD, R. R. S. Estrutura de utilização dos jogos de empresas nos cursos de graduação em administração e ciências contábeis do país e avaliações preliminares de uma disciplina baseada neste método. In: Anais XVII ENANGRAD, 2006.

BERRETINI, A.; CAMPOS, R. Modelos de processos para jogos de empresas na área de planejamento e controle da produção. XXX Encontro Nacional de Engenharia de Produção. São Carlos, SP, Brasil, out/ 2010.

CARNIEL, A. Especificação de um ambiente para o trabalho e o aprendizado em grupos colaborativos na Internet. Dissertação (Mestrado em Engenharia de Produção e Sistemas), UFSC, Florianópolis, 2002.

CRA. VI Encontro de Coordenadores de Cursos de Administração. Florianópolis, 2011.

FARIA, A. A. O uso educacional dos computadores: um estudo da formação dos administradores de empresas. Dissertação (Mestrado em Administração de Empresas), EAESP-FGV, São Paulo, 1997.

FERRANDÉZ, A.; SARRAMONA, J.; TARIN, L. Tecnología didáctica: teoría y práctica de la programación escolar. Barcelona: CEAC, 1977.

GERBER, J. Z. Proposta de metodologia para o desenvolvimento de recursos à aplicação de Jogos de Empresas via Internet. Dissertação (Mestrado em Engenharia de Produção e Sistemas), UFSC, Florianópolis, 2000.

GRAMIGNA, M. R. M. Jogos de empresas e técnicas vivenciais. São Paulo: Makron Books, 1995.

GROFF, J.; et al. Console game-based pedagogy: A study of primary and secondary classroom learning through console video games. International Journal of Game-Based Learning. 2(2), p. 35-54, 2012.

HAIDT, R. C. C. Curso de didática geral. São Paulo: Ática, 1995.

JACKSON, T. European management learning: a cross-cultural interpretation of Kolb's learning cycle. Journal of Management Development. England, MCB University Press, v.14, n.6, p.42-50, 1995.

KOLB, D. A. et al. Psicologia organizacional: uma abordagem vivencial. São Paulo: Atlas, 1978.

LACRUZ, A. J.; VILLELA, L. E. Percepção dos participantes de jogos de empresas quanto às condições facilitadoras para o aprendizado em programas de simulação empresarial: um estudo exploratório. ADM MADE, Rio de Janeiro: UNESA, v.8, n.10, p.175-202, jul./dez. 2005.

Revista Eletrônica de Estratégia \& Negócios, Florianópolis, v.7, n.2, mai./ago. 2014. 
LÉGER, P. M. Using a simulation game approach to teach ERP concepts. Cahier du GReS, Quebec, 2006.

MAHBOUBIAN, M. Educational aspects of business simulation softwares. Procedia Social and Behavioral Sciences, vol. 2, Issue 2, p. 5403-5407, 2010.

MARQUES FILHO, P.A. Jogos de empresas: uma estratégia para o ensino de Gestão de Tomada de Decisão. Dissertação (Mestrado em Engenharia de Produção), USP, São Paulo, 2001.

MARTINELLI, D. P. A utilização dos jogos de empresas no ensino de administração.

Dissertação (mestrado). FEA-USP. São Paulo, 1987.

MILES, W. G.; BIGGS, W. D.; SCHUBERT, J. N. Student perceptions of skill acquisition through cases and general management games: a comparison. Simulation \& Games, v. 17, n. 1, p. 724, Mar., 1986.

PRETTO, F.; FILARDI, F.; PRETTO, C. Jogos de empresas: uma estratégia de motivação no processo de ensino e aprendizagem na teoria das Organizações. Revista Eletrônica de Estratégia e Negócios, Florianópolis, v. 3, n. 1, jan./jun. 2010.

PROTIL, R. M; FISCHER, H. Utilização de simuladores empresariais no ensino de ciências sociais aplicadas: um estudo na República Federal da Alemanha. Revista de Economia, Curitiba: Editora UFPR, v.31, n.2, p. 113-134, jul./dez. 2005.

RAFALSKI, J. P.; CARNEIRO, C. M. C. D. Jogos empresariais para apoiar o desenvolvimento de habilidades profissionais foco. Revista de Administração da Faculdade Novo Milênio, v.6. n. 1, nov. de 2013.

RUAS, R. Mestrado modalidade profissional: em busca da identidade. RAE - Revista de Administração de Empresas, v. 43, n. 2. 2003.

SÁ SILVA, P. et al. Simulation, games and challenges: from schools to enterprises. 7th International Workshop on Enterprise and Organizational Modeling and Simulation, EOMAS, vol. 88 LNBIP, p. 63-73, 2011.

SAUAIA, A. C. A. Conhecimento versus desempenho das organizações: um estudo empírico com jogos de empresas. Revista Eletrônica de Administração-REAd, ed. 49, v. 12, n.1, jan./fev. 2006.

SAUAIA, A. C. A. Laboratório de Gestão: Simulador Organizacional, Jogo de Empresas e Pesquisa Aplicada. 1 ed. Barueri, SP: Manole, 2008.

SAUAIA, A. C. A. Jogos de empresas: aprendizagem com satisfação. Revista de Administração. São Paulo, v.32, n.3, p. 13-27, jul./set., 1997.

Revista Eletrônica de Estratégia \& Negócios, Florianópolis, v.7, n.2, mai./ago. 2014. 
SAUAIA, A. C. A. Satisfação e aprendizagem em jogos de empresas: contribuições para a educação gerencial. Tese (Doutorado em Administração), Curso de Pós-Graduação em Administração, Faculdade de Economia, Administração e Contabilidade da USP, 1995.

SAUAIA, A. C. A; et al. Relação entre Conhecimento e Desempenho Gerencial: Análise do Aprendizado dos Participantes de um Jogo de Empresas. Anais XXXIV ENANPAD, 25 a 29 de setembro. 2010.

SILVA, C. R. O. Bases pedagógicas e ergonômicas para a concepção e avaliação de produtos educacionais informatizados. Dissertação (Mestrado em Engenharia de Produção), UFSC, Florianópolis, 1998.

SNOW, S. C.; GEHLEN, F. L.; GREEN, J. C. Different ways to introduce a business simulation: the effect on student performance. Simulation Gaming, v. 33, n. 4, p. 526-532, 2002.

STAHL, L. M.; LOPES, P. C. Estratégias de avaliação para jogos de empresas gerais: avaliando desempenho ou aprendizagem. Enanpad, 2004.

TANABE, M. Jogos de e Empresas. Dissertação (Mestrado). Faculdade de Economia, Administração e Contabilidade, Universidade de São Paulo, São Paulo, 1977.

TAPSCOTT, D. Growing up digital: the rise of the net generation. McGraw Hill: New York, 1997.

Revista Eletrônica de Estratégia \& Negócios, Florianópolis, v.7, n.2, mai./ago. 2014. 